\title{
On the Performance of the Principle of Equitable and Reasonable Utilization in the Practice of the Utilization of Transboundary Water Resources
}

\author{
Yanmei HE \\ Shanghai University of Politics and Law, Shanghai, China
}

\begin{abstract}
The principle of equitable and reasonable utilization is the fundamental one of International Water Law, which is generally established by international water treaties and soft law documents. It is better performed in the practice of the utilization of transboundary water resources. China can use it to participate in the development and utilization of Mekong river basin equitably.
\end{abstract}

Keywords: equitable and reasonable utilization, transboundary water resources, downstream benefits, equitable sharing

\section{1 引言}

跨國水資源即跨國淡水資源，又稱為國際水資源或 共用水資源，包括國際河流、湖泊及其大小支流，或者 國際河流的入口和出口, 以及處於兩國或更多國家管轄 之內的地下水系統, 通常稱為國際流域或國際水道, 以 國際河流和湖泊為主體。全球約有 263 條影響較大的國 際河流和湖泊，分佈在 145 個國家。這些河流和湖泊擁 有全球 $60 \%$ 的淡水資源，居住著世界約 $40 \%$ 的人口，流 域面積占地球陸地面積的 45. 3\%[1]。

跨國水資源的分配，或者更準確地說，重新分配 通過與每個特定情況相關的所有因素的權衡來實現。 這種方法來自于國際水資源法的首要原則一公平和合 理利用原則。在跨國水資源日益短缺的時代, 水道國 首先關注的是預防和解決對跨國水資源日益強烈的需 求競爭所導致的使用衝突。要預防和解決衝突, 必須 解決三個基本問題: 確立法律權利; 設立分配框架; 建立遵守機制 ${ }^{1}$ 。對公平和合理利用的確定構成解決法 律權利問題的基礎, 因為國家活動的合法性是根據這 一基本原則評估的，除非另有協議。

\section{2 公平和合理利用原則的含義與理論基礎}

\section{1 公平和合理利用原則的含義}

${ }^{1}$ 首先是確立法律所有權, 認定所有的利害關係者並設立其獲得所 有權的機制; 其次是設立分配框架, 這個框架的理想狀態是靈活 的、可預測的, 並且能夠實施; 最後還需要建立監管和強制遵守 機制、避免和和平解決爭端的機制。
公平和合理利用原則是指國際水道各沿岸國有權 公平和合理地分配和利用跨國水資源。

公平和合理利用不僅是指水量, 而且是指水質。 否則將會造成不公平的結果, 或者對沿岸國帶來損 害。典型的例子是美國與墨西哥對其界河科羅拉多河 水的分配。兩國於 1944 年簽訂了《關於利用科羅拉多 河、提華納河和格蘭德河從德克薩斯州奎得曼堡到墨 西哥灣水域的條約》, 分配了水量, 但是條約未提及水 質問題，導致十多年後由於美國新建抽水廠和新式灌 溉系統, 把含鹽度高的水引入科羅拉多河中, 致使河 水鹽度急劇增高, 給墨西哥境內的農作物造成損害。 在經多次碰商後, 兩國於 1973 年簽訂了《關於永久徹 底解決科羅拉多河含鹽量的國際問題的協定》, 協定要 點是, 美國通過修建河水淡化工程等各種措施, 控制 河水含鹽量, 保證墨西哥根據 1944 年條約有權享用之 水的大部分不超過條約所規定的含堿標準, 從而解決 兩國關於水質問題的糾紛。其實早在西元前 2400 年左 右, 西亞地區曾孕育了世界古代文明之一的美索不達 米亞文明的兩河平原 (底格裏斯河和幼發拉底河), 由 於灌溉用水的蒸發使土壤表面鹽的含量增加, 鹽鹼化 作用致使美索不達米亞地區的穀物產量大幅度下降。 幾百年後, 美索不達米亞文明就從地球上消失了。土 壤鹽鹼化是毀滅這一文明的原因之一。因此, 共用水 資源的利用不應局限於水量的分配和分享, 而應是水 量和水質並重。

公平和合理利用原則不僅適用于地表水，也適用 於地下水。因為地表水和地下水都是水文圈的一部 
分，不僅所涉水文、經濟和工程變數基本相同，而且 兩者可以相互轉換, 對兩種來源的水的法律規範也必 須是相同的。最高權威公法學家已總結出, 對地下水 的主權必須以對地表水的主權同樣的方式受到限制, 因 此地下水受到適用于地表水的公平利用原則的約束 ${ }^{2}$ 。

\section{2 公平和合理利用原則的理論基礎}

公平和合理利用原則來源於 “運用你自己的財產 但不要傷害別人” 這一習慣法, 以相對領土主權理論 為基礎，因為它承認和評估共用水道的所有國家的共 用性和競爭性的利益。

相對領土主權理論是指, 國家在行使自身的主權 時, 應以不損害他國的主權和利益為限。主權只能是 相對的, 國家不能總是為所欲為, 其主權應受到或多 或少的限制。這是由對等原則所決定的, 而對等原則 可以說反映了國際法規範的本質特徵。

在相對領土主權理論下，國家對國際水道內的水 資源享有開發和利用的主權權利, 但受到其他沿岸國 相應的主權權利的約束。“各國都承認所有沿岸國利 用一部分共同水源的權利, 以及對這種利用進行管理 從而不干擾其他沿岸國的類似利用的義務[2]。” 根據 這一理論, 各國自由地利用其領土內的水, 只要不對 其他沿岸國的權利和利用造成重大損害。這種權利和 義務的平衡, 反映了國家積極面對淡水資源日益短缺 的現實, 尋求避免和解決水資源利用衝突的期望。

\section{3 公平和合理利用原則的地位}

公平和合理利用原則是國際水資源法的基本原 則, 它不是全球水夥伴組織 2000 年行動框架所述的 “妥協” 的原則, 而是構成一般國際法, 是習慣國際 法規則的結晶。公平和合理利用原則獲得了國際社會 的廣泛承認, 可以由條約、軟法檔、國際和國內司法 實践等證明。

\section{1 國際條約的規定}

許多國際水條約, 包括雙邊水條約、多邊水條約 和全球性水條約在內, 都以專門條款確認國際水道各 沿岸國或國際流域各國公平和合理利用水資源的權 利, 比如 1929 年 《多明尼加與海地和平、友好和仲裁 條約》第十條、1990 年《尼日爾一尼日利亞共同水資 源協議》第二條、1992 年赫爾辛基公約第二條第二款

${ }^{2}$ Caponera, Teclaff, Utton, A., Benvenisti, Barberis, Hayton, Schwebel, and so on. (c)項、1994 年《多瑙河公約》第二條第一款、1995 年《湄公河流域可持續發展合作協議》第五條、1995 年《南部非洲發展共同體關於共用水道系統的議定書》 第二條第六款、2002 年《茵克馬提一馬布多水道臨時 協議》第三條、2002 年《沙瓦河框架公約》第七條, 等等。1997 年《國際水道非航行使用法公約》作為規 範跨國水資源利用的第一個全球性公約，在第五條重 申了公平和合理利用原則, 第六條還列舉了確定公平 和合理利用應考慮的各個因素，包括科學、經濟和環 境因素，可稱之為 “因素清單”。早期的某些條約未 明確規定公平和合理利用, 但是其規範事項卻體現了 這一原則, 比如 1919 年《對德和約》、1921 年《國際 性可航水道公約與規約》和 1961 年《加拿大與美國關 於合作開發哥倫比亞河流域水資源的條約》(以下簡稱

“哥倫比亞河條約”)。《對德和約》賦予法國利用萊 茵河水發電的排他性權利, 但是法國需向德國支付所 產生的能源價值的一半; 《國際性可航水道公約與規 約》的規約部分第十條第二款建議下游收益甚至是上 游利益的分享, 如果一締約國有義務採取措施改進河 流航行或投入花費以維持其航行, 它有權要求其他沿 岸國合理地分擔成本; 哥倫比亞河條約第二條一第八 條明確而具體地規定了公平分享下游收益的方法。

\section{2 軟法文件的規定}

國際法協會 1958 年通過了《國際法原則聲明》, 指出在條約或習慣規範沒有明確規定的情況下，國際 流域各國 “有權公平和合理地分享流域水利用的水 益”。國際法協會 1966 年通過的《國際河流利用規則》 （即著名的赫爾辛基規則）第四條規定，每個流域國 在其境內有權公平和合理地分享國際流域內水利用的 水益, 並在第五條列舉了因素清單, 這一清單為《國 際水道非航行使用法公約》第六條所借鑒。1972 年召 開的人類環境會議通過的《行動計畫》的建議涉及河 流和湖泊的污染。關於 “一國以上管轄的共同水資 源” 的第 51 號建議指出，“一國以上管轄的共同水域 的基本利益應由有關國家公平分享”。1977 年在阿根 廷的馬德普拉塔的國際水會議通過了《馬德普拉塔行 動計畫》, 該計畫的第 91 號建議書中宣佈, 並于共有 水資源的利用、管理和開發，國內政策應顧及到各國 公平利用該資源的權利[3]。歐洲委員會 1984 年通過 的《關於水的合理利用的原則宣言》指出，水益的利 用和分配都必須是合理的。國際法協會 2004 年通過的 《關於水資源的柏林規則》也編纂和進一步發展了公 
平和合理利用原則, 在其第十二條和第十三條分別規 定了公平和合理的利用和參與原則, 以及因素清單。

\section{3 司法判例的確認}

在國際法院 1997 年判決的多瑙河蓋巴斯科夫大 壩案中, 國際法院數次提到公平和合理利用原則, 認 定捷克斯洛伐克單方面分流多瑙河水的行為 “剝奪了 匈牙利公平和合理地分享多瑙河自然資源的權利” 3 這是對作為習慣國際法規範的公平和合理利用原則的 強烈認同。

\section{4 公平和合理利用原則在跨國水資源利用 實踐中的運用}

公平和合理利用原則不僅體現在國際水條約和軟 法檔中, 在實踐中也獲得了較為廣泛的運用。研究有 關案例, 可以使我們更加深刻地理解公平和合理利用 原則的實質, 為目前某些國際河流水爭端的解決提供 有益思路。

\section{1 聯合專案收益的共同分享}

赫爾辛基規則確立了公平和合理利用原則後, 很 多雙邊和多邊水條約都確認了這一原則, 以專案聯合 開發為目的或主要內容的雙邊水條約, 還規定了聯合 專案收益共同分享的方法。1977 年，匈牙利與捷克斯 洛伐克達成《關於蓋巴斯科夫-拉基瑪洛堰壩系統建設 和運營的條約》, 規定作為 “聯合投資”, 由兩國以各 自的成本在各國領土內開展大壩建設專案, 並且平等 地分享水電、航行、防洪等收益, 這體現了公平和合 理利用原則。1978 年, 條約生效, 雙方開始履行條約, 在各自領土內建設大壩, 但是由於匈牙利認為該工程 將導致在條約達成當時不能預見的損害, 中止執行條 約, 斯洛伐克執行臨時解決方案, 雙方為此發生爭端, 將爭端提交國際法院解決。法院在判決中認為斯洛伐 克單方面分流多瑙河水的行為剝奪了匈牙利公平和合 理利用多瑙河水的權利, 並將該原則作為國際水法的 基本原則。這是公平和合理利用原則第一次在國際判 例中得到適用。1996 年, 印度與尼泊爾達成《關於馬 哈卡利河聯合開發的條約》, 規定雙方在恒河的支流, 也是雙方界河的馬哈卡利河上合作建設一項多目的工 程。該工程旨在通過發電、灌溉利用和防洪為雙方產

${ }^{3}$ See Judgement of September 25 1997, 1997 ICJ No. 92, Para. 85. ${ }^{4}$ See Art. 3 of 1996 Treaty between Nepal and India Concerning the Integrated Development of the Mahakali River.
生最大的收益, 這些收益將在連續的基礎上進行評估 以確保收益的最大化。雙方將以一體化的方式合作， 以開發和共用它們共同的水資源。這一項目包括在兩 國各自的河段建設同等能力的發電站, 兩個電站將一 同運營, 所產生的總能源將由印度和尼泊爾雙方平等 地分享; 兩國將根據它們所獲得的收益的比例分擔工 程成本，尼泊爾所享有的能源份額將賣給印度 ${ }^{4}$ 。

\section{2 下游收益的公平分享}

\subsection{1 哥倫比亞河條約確立的公平分享下游收益原則}

哥倫比亞河源於加拿大，是加拿大與美國之間的 界河，也是北美第四大河流，河水落差較大，使水力 發電成為流域的最佳利用途徑之一。哥倫比亞河條約 以公平利用原則為基礎，是跨國水資源合作開發和利 用的獨特模式, 解決了美國和加拿大從十九世紀四十 年代中期到六十年代中期長達二十年的哥倫比亞河水 爭端。

哥倫比亞河條約規定，雙方享有利用哥倫比亞河 水資源的權利。條約明確承認, 位於加拿大的三個大 壩項目的建設和運營既可增加美國發電廠的電力, 也 可為美國提供灌溉和洪水控制收益, 沒有三個大壩項 目, 所有這些收益用相同的成本是不可能得到的。加 拿大同意開發蓄水設施以增強美國水力發電的開發和 洪水控制, 作為在加拿大境內建設三個大壩專案的回 報, 條約特別賦予加拿大因為洪水控制而獲得一次性 現金支付的權利，以及美國發電廠因加拿大的貯存而 產生的額外電力的一半。水電收益是按加拿大蓄水設 施和流量調節開始之前和之後美國水力發電之間的差 別來計算的。締約方同意, 允許加拿大在美國國內處 理其水力收益（即將美國提供給加拿大作為補償的電 力再銷給美國)。洪水控制收益是依據預計發生洪水要 預防的損害來計算的。

哥倫比亞河條約並未明確提到哥倫比亞河的公平 和合理利用, 但是它所確立的分享下游收益原則是公 平與合理利用原則的體現, 下游收益方案是公平分享 水益的革新性方法。用 Bourne 的話說, “這一原則的 本質是, 當一流域國從事或阻止從事某項行為, 從而 給共同流域國帶來利益, 該共同流域國（後者）有義 務與該流域國（前者）分享這一利益[4]。”加拿大對 在其境內所建設的蓄水項目微有利用, 結果遭受了 “損害”, 但也得到了補償: 一半的水電額外收益, 以及美國避免洪水損害的金錢價值。加拿大不需要這 些電力, 可以將其返銷給美國。 


\subsection{2 其他條約對公平分享下游收益原則的運用}

哥倫比亞河條約體制確立的下游收益的公平分享 原則，在其他條約中也得到確立和運用。1984 年, 南 非和葡萄牙籤訂《Cunene 河流域協議》。根據該協定 第四條, 葡萄牙在安哥拉境内的 Cunene 河上游建設 大壩, 並運營大壩以調節流量, 抽取經調節後的河流 流量不超過 50\%。南非支付葡萄牙對該工程的建設費 用和運營費用, 而且還為被占土地和工程導致的洪水 支付一筆固定的費用[4]; 1986 年，南非和萊索托簽訂 《萊索托高地水項目條約》, 同年十月生效, 條約規定 上游國萊索托建設大壩設施, 南非為確保自己獲得源 於萊索托上游的水量, 同意負擔在萊索托建設的大壩 設施的絕大部分成本。這些設施除了控制上游跨界水 到南非的流量, 還向萊索托提供水力發電。這些例子 有一個共同的特點, 即確定了下游收益的公平分享,

一國或一些國家因另一國或一些國家從事的行為而獲 得的收益, 與另一國或一些國家進行分享, 或者以現 金形式作為回報。凡此種種, 通過對各方重要的問題 的相互銜接, 滿足了兩個國家各不相同的需要, 解決 了他們之間的水衝突。這是公平和合理利用原則的直 接體現和具體運用。

公平分享下游收益的例子帶來我們許多啟示。首 先, 只要下游國有與上游國分享收益的誠意, 上下游 國都能從共用水資源的公平和合理利用中獲得收益, 實現共贏; 其次, 流域各國必須彼此進行合作, 通過 協商和談判達成流域水條約, 為跨國水資源的公平和 合理利用提供法律依據。正是公平和合理利用這一指 導性法律原則的採納為實現哥倫比亞河爭議的解決提 供了框架。目前的許多國際水爭端, 比如尼羅河水爭 端、約旦河水爭端、恒河水爭端等, 都可嘗試通過公 平分享下游收益獲得解決, 使這些國家從競爭對手轉 變為潛在的合作夥伴, 但是應顧及公平和合理利用原 則的新發展, 尤其是便利所有沿岸國的公平參與。在 瀾滄江一一涺公河流域水資源利用中，也可嘗試通過 所有沿岸國的公平參與 實現對下游收益的公平分享。

\section{3 中國參與瀾滄江一湄公河流域水資源公平和 合理利用的設想}

瀾滄江一湄公河源於中國的青藏高原, 在中國境 內稱為瀾滄江, 流經緬甸、泰國、柬埔寨、老擑和越 南, 最後注入南海。瀾滄江一湄公河流域有長期的合 作歷史, 瀾滄江水資源聯合開發有其堅實的法律依據

${ }^{5}$ 目前, 下湄公河僅有 500 兆瓦的裝機容量, 而中國境內的河段有 1500 兆瓦的裝機容量。
和較好的組織基礎。早在 1957 年，在亞洲和遠東經濟 委員會的支持下, 泰國、柬埔寨、老捛和越南等四個 下游國家建立了下涺公河流域調查協調委員會。從 1978 年開始, 由於柬埔寨在委員會的缺席, 又建立了 涺公河臨時委員會。1995 年, 在聯合國開發計畫署的 指導下，泰、柬、老、越四國達成《湄公河流域可持 續發展合作協定》, 根據協定建立了湄公河委員會, 取 代了下湄公河流域調查協調委員會和涺公河臨時委員 會。湄公河委員會的使命是, 為了國家的互利和人民 的福利, 通過實施戰略規劃和活動, 以及提供科學資 訊和政策建議, 促進和協調水和有關資源的可持續管 理和開發[5]。根據條約規定, 四成員在涺公河流域水 和有關資源的可持續開發、利用、管理和保全的所有 領域進行合作，包括但不限於灌溉、水電、航行、防 洪、漁業、浮運木材、娛樂和旅遊。從事這些活動時 應使所有沿岸國的多種利用和互利達到最佳, 並使有 害影響降低到最低程度。遺憾的是, 協定和組織機制 缺少兩個上游國中國和緬甸的參與。近年來, 湄公河 委員會與中國頻繁接觸, 要求中國提供瀾滄江的水文 資料和梯級電站規劃資料, 並試圖推動中國加入協定 和委員會。中國近幾年在電力、環境、交通和人力資 源開發等領域與委員會成員國進行廣泛對話和合作。

從流域年徑流量來看，流域內的水資源可以滿足 灌溉、水電、航行和旅遊等經濟增長的需求。但是流 域的水流量因熱帶風氣候而有戲劇性變化，每年 5-12 月份為濕季, 巨大流量導致嚴重洪災; 12 月份到次年 4 月份為幹季, 水量嚴重短缺, 導致家庭用水和農業 用水短缺, 船舶航行受到限制, 並使流域的海灣平原 持續遭受鹽水入侵。老過嚴重依賴河流運輸, 而幹季 流量的減少對航行帶來不利影響; 泰國和越南數十年 來開發了深灌溉系統, 而這一系統的利用在幹季受到 嚴重限制; 越南海灣持續遭受鹽水入侵。因此, 流域 水資源利用的關鍵問題是幹季期間水資源的公平分享 和可持續開發。湄公河流域有爭議和需要解決的主要 問題，也是對流域在幹季水資源的分配和利用。

流域水文現實要求建立水貯存工程, 將濕季的巨 大流量貯存以供幹季時使用, 而水電專案可以滿足這 一需要。中國作為瀾滄江一㴮公河流域的上游國, 有 最為豐富的水能資源, 最適宜建立大壩開發水電 ${ }^{5}$ 。但 是流域各國由於關注點和開發目標不同，在對水資源 的利用上難免存在利益衝突, 主要集中在水量分配和 水生生態兩個方面。上游國最為關注的是航運和水電 建設, 下游國則偏重灌溉、防洪、漁業、環境保護等。 中國在瀾滄江上游建設和運營大壩, 下游國擔心會影 
響其灌溉用水、防洪和漁業生產，造成環境損害，而 持懷疑和反對態度。

沣公河流域各國就水資源利用達成一致的關鍵, 是尋找可接受的方法, 它既提供善意合作機會, 又確 保根據主權平等原則, 任何當事方都不會處於不利。 下游收益的公平分享無疑是這一方法之一, 甚至是最 佳方法。這一方法的適用形勢也很迫切, 因為各國對 湄公河都有切實的利益, 而且都在進行或計畫進行水 資源開發項目。泰國在湄公河流域有水電、水庫、水 資源開發、沉積、灌溉、水量和水質等利益要求, 近 年來已在研究從㴮公河分流水的方案, 以及從湄公河 的泰國支流進行流域間分流的方案; 老抰有水電開 發、灌溉和土地利用、森林變化等方面的利益, 它計 畫在湄公河的老抯支流建設一些中等規模的水力發電 專案; 柬埔寨有水電開發、魚類回游、增加灌溉面積 等利益要求, 緬甸有航行、灌溉等利益要求, 越南有 防洪、灌溉、排斥海水入侵等利益要求, 中國有水力 發電等利益要求, 已在瀾滄江上游建立多個水電大 壩, 帶來水電、泥沙沉積、防洪等收益, 正在與泰國 進行出口電力的談判。

二十世紀九十年代以來，隨著世界經濟全球化、 一體化趨勢加強, 在鄰國經濟向區域化方向發展的大 趨勢下, 瀾滄江一湄公河流域的中國、老擑、緬甸、 泰國等四國, 形成了加快次區域經濟合作進程的共 識, 在交通、能源、礦產、貿易、旅遊等多領域的合 作迅速展開。交通運輸是各國經濟發展的驅動力, 是 貿易往來、人員交流的重要紐帶, 流域各國都把瀾滄 江一湄公河航運的開發利用列為次區域經濟合作的重 要內容和優先領域。四國於 2000 年簽訂了《瀾滄江一 湄公河商船通航協定》, 2001 年 6 月, 四國通航聯合 協調委員會正式組建並開始工作, 四國商船正式通航

2002 年 9 月, 湄公河流域的合作努力取得了重大 突破: 全球環境基金投入了 1.1 千萬美元的資金, 旨 在推動四個下游國共同改進流域可持續管理。這筆資 金將支持湄公河委員會及成員國, 確保他們以保全環 境的可持續的方式開發水資源。世界銀行已看出了水 電項目藴藏的巨大收益, 因為這一項目能夠貯存濕季 徑流量, 以便在幹季發電[4]。如果湄公河沿岸各國能 夠公平參與水電開發專案, 使世界銀行確信這一專案 的運營不會造成可察覺的損害, 這一項目就有望獲得 世界銀行的資助 ${ }^{6}$ 。這對吸引中國和緬甸加入協定, 成 為委員會的成員國, 提供了好的機會。筆者認為, 如

\footnotetext{
${ }^{6}$ 世界銀行對那些可能導致對他國領土可察覺的損害的項目不提供 資金支援，除非有參與和建議公平分配的所有利害關係方的支 持。
}

果下游國家因為中國在上游建設和運營大壩而獲得一 些收益, 應該給予中國以相應補償, 這體現了下游收 益的公平分享, 完全符合公平和合理利用原則。

流域各國在達成協議以前, 可通過諸如在下游收 益的計算等事項上的技術合作建立信任, 在此基礎上 開展流域條約的談判和簽訂工作。因為只有雙方首先 能夠在技術層面上建立信任和諒解, 才能最終達成條 約, 就下游收益進行公平分享。在哥倫比亞河條約體 制建立的最初階段, 加拿大和美國在上游開發專案上 的主要障礙是兩國科學家和技術人員不能就水流量、 大壩高度、下游收益的計算等技術問題達成一致。這 使兩國對發電能力和發電的單位成本作出不同估價, 也不能對下游收益的範圍達成一致[4]。科學家集團之 間的這種分歧如果只靠搜集更多資料，永遠也不能得 到解決。只有科學家集團之間達成諒解, 下游收益的 計算才具有確定性, 並就談判和簽約取得進展。當然, 最終是否能夠合作開發還取決於政治家的意願。

\section{5 結語}

公平和合理利用原則是國際水資源法的核心原 則, 是國際習慣法規則的結晶, 是相對領土主權理論 的體現, 這一原則的實施需要通過權衡國際水道各沿 岸國的科學、經濟和其他要素來實現。公平和合理利 用原則在跨國水資源利用領域也獲得了較為廣泛的運 用, 通過對相關國家的運用實踐和具體案例進行分析 可以看出, 主要有聯合項目收益的共同分享、下游收 益的公平分享等兩種運用方法。以專案聯合開發為目 的或主要內容的雙邊水條約, 規定了聯合項目收益共 同分享的方法; 哥倫比亞河條約確立的公平分享下游 收益原則, 在其他條約中也得到確立和運用。目前的 許多國際水爭端, 比如尼羅河水爭端、約旦河水爭端、 恒河水爭端等, 都可嘗試通過公平分享下游收益獲得 解決, 使這些國家從競爭對手轉變為潛在的合作夥 伴, 但是應便利所有沿岸國的公平參與。在瀾滄江一 涺公河流域水資源利用中, 也可嘗試通過所有沿岸國 的公平參與, 實現對下游收益的公平分享。

\section{REFERENCES}

[1] Wouters, P. K. and Clarke, A. R. "The Role of International Water law in Promoting Sustainable Development," International Water Law Research Institute Website, visited on February 32004. 
[2] Fathallah, R. M., "Water Disputes in the Middle East: An International Law Analysis of the Israel-Jordan Peace Accord [J]”, Land Use and Envtl. L., Vol. 12, No. 1, pp. 138, Fall 1996.

[3] 韓健, 陳立虎. 國際環境法 [M]. 武漢大學出版社, 1992. 96.

[4] Paisley, R., "Adversaries into partners: International Wa- ter Law and the Equitable Sharing of Downstream Benefits," Melbourne Journal of International Law, pp. 286-299, October 2002.

[5] Mekong River Commission: Establishment and Functions, http://www.imf.org/external/np/sec/decdo/mrc.htm,visited on 23, September 2008. 